\title{
The Infectious Diseases Act and Resource Allocation during the COVID-19 Pandemic in Bangladesh
}

\author{
Md. Sanwar Siraj ${ }^{1}$ (D) Rebecca Susan Dewey $^{2}$ (D) A. S. M. Firoz UI Hassan ${ }^{1}$
}

Received: 9 July 2020 / Revised: 15 September 2020 / Accepted: 24 September 2020 / Published online: 17 October 2020

(C) National University of Singapore and Springer Nature Singapore Pte Ltd. 2020

\begin{abstract}
The Infectious Diseases (Prevention, Control and Eradication) Act entered into force officially on 14 November 2018 in Bangladesh. The Act is designed to raise awareness of, prevent, control, and eradicate infectious or communicable diseases to address public health emergencies and reduce health risks. A novel coronavirus disease (COVID-19) was first identified in Bangladesh on 8 March 2020, and the Ministry of Health and Family Welfare issued a gazette on 23 March, listing COVID-19 as an infectious disease and addressing COVID-19 as a public health emergency. The gazette empowers the government to monitor the spread of infection. Despite there being an infrastructure of research ethics committees in almost all hospitals in Bangladesh, a lack of such committees in the clinical setting often forces healthcare professionals to allocate scarce healthcare resources to the task. These personnel are often either influenced by materialistic matters or guided by the emergency policies, without reaching a consensus on how to allocate scarce resources in times of need, especially in the time of the COVID-19 pandemic. Ethical dilemmas often arise when a number of patients with COVID-19, especially in poor and middle-class areas, are denied care while elites are prioritized to receive such scarce resources. Resource allocation in healthcare during the COVID-19 pandemic in Bangladesh appears to be unethical and in direct conflict with the biomedical principles of non-maleficence and procedural justice. The findings of this study suggest that the Act needs substantive changes in the stipulation of policy directing hospitals in the provision of resource allocation framework. Furthermore, parliament should produce guidance outlining how to successfully implement the law with the aim of protecting public health in times of emergency, especially the COVID-19 pandemic.
\end{abstract}

Keywords Infectious diseases $\cdot$ Resource allocation $\cdot$ Coronavirus $\cdot$ Pandemic $\cdot$ Bangladesh

Md. Sanwar Siraj

siraj_sanwar@juniv.edu

1 Department of Government and Politics, Jahangirnagar University, Savar, Dhaka, Bangladesh

2 Sir Peter Mansfield Imaging Centre, University of Nottingham, Nottingham, UK 


\section{Introduction}

Legal documents guide policy makers, administrators, and healthcare professionals to manage and contain the spread of infectious diseases across a country. The Infectious Diseases (Prevention, Control and Eradication) Act was first passed by the parliament and came into force officially on 14 November 2018 (Infectious Diseases (Prevention, Control and Eradication) Act 2018). The Act is designed to raise awareness of, prevent, control, and eradicate infectious or communicable diseases in order to address public health emergencies and reduce the risk to public health.

This study presents the scope of this Act, the determination of the definition of infectious disease, duties, and functions of the Directorates; the formation, functions, and responsibilities of the Advisory Committee. The article outlines instructions from the World Health Organization (WHO), in terms of sample collection and testing, disinfection or closure of infected places or installations, provisions relating to infected goods, vehicles, areas, and patients, and prohibition of import and export. Finally, the provisions with regard to punishments for law breakers are addressed. Some primary ethical dilemmas arise with regard to resource allocation in medicine and healthcare in times of emergency, specifically within the setting of the COVID-19 pandemic.

Bangladesh is a densely populated country with population densities of more than 1200 inhabitants $/ \mathrm{km}^{2}$ (World Bank 2018). With pervasive poverty and hunger, Bangladesh regularly faces challenges including a low purchasing power parity rate and low adult literacy rate, malnutrition of newborn babies and mothers, overcrowding of public healthcare services, limited sanitation, floods, and environmental disasters. The population was adversely affected by the tsunami in 2004. A number of earthquakes and cyclones in the past few years including the cyclone Amphan in 2020 have caused serious damage to life and property, leaving many homeless, displaced, or dead. The government was forced to allocate funds to provide food and shelter for the population as a part of the post-disaster strategy. The country has also been affected by locust swarm infestations, and the incidence of dengue fever has increased in the last few years. The dengue outbreak started in Bangladesh in 2000, it was severe in 2019 , and still the threat is ongoing. It was estimated that more than 100,000 patients were hospitalized with dengue fever in 2019, with 164 deaths (UNB 2019). The lack of a comprehensive awareness program, preparedness for the outbreak, and a supportive clinical management framework increased the severity of the dengue infection and mortality rates in the country (Mamun et al. 2019). This has strained the underfunded public healthcare system, which is further exacerbated in times of crisis, especially the COVID-19 pandemic. The legal framework for ethical decision-making regarding clinical resource management should assist healthcare workers worldwide make decisions about who should receive care and on what basis. As such, an ethical framework is absent in Bangladesh; the need for an effective legal framework for the preparedness of enacting measures and allocating scarce medical resources within the healthcare system is significant for Bangladesh. 


\section{Scope of the Act}

\section{Definition of Infectious Diseases}

The Act is referred to as the Infectious Diseases (Prevention, Control and Eradication) Act. It defines what is meant by an infectious disease, and addresses measures for the prevention, control, and elimination of such diseases in Bangladesh. Section 4 of the Act contains a list of diseases that fall within the definition of the Act. It defines infectious diseases as including the following diseases: malaria, kala-azar, filariasis, dengue fever, influenza, avian flu, Nipah, anthrax, MERS-CoV, rabies, Japanese encephalitis, diarrhea, tuberculosis, respiratory tract infections, HIV, viral hepatitis, diseases preventable through vaccination, typhoid, food poisoning, meningitis, Ebola, Zika, and Chikungunya. Under the Act, the definition of infectious diseases above is not exclusive. It prescribes that the government may therefore declare any emerging or re-emerging issues as infectious diseases by notification in the official gazette (Section 4). The novel coronavirus disease (COVID-19) was first identified in Bangladesh on 8 March 2020, and in fact the High Court directed the government to issue an official gazette declaring COVID-19 as an infectious disease within the meaning of the Act. The Ministry of Health and Family Welfare (MOHFW) therefore issued the circular as per the stipulations of the Act on 19 March and issued a gazette on 23 March listing COVID-19 as an infectious disease, and therefore a public health emergency (The Daily Star 2020). The government issued the gazette to protect people from contagious diseases under Section 32. The gazette has empowered the government to take action against people who do not follow government directions, in order to monitor the spread of contagious respiratory infections.

\section{Duties and Functions of the Directorate of Health}

The Act defines the duties and functions of the Directorate of Health (Section 5). It includes initiatives including the formulation of strategies to prevent, control, and eradicate infectious diseases; protect the people from their national and international spread; and the provision of assistance from government and non-government organizations and domestic and international organizations for the implementation of the strategies. It prescribes Health Directorates to take necessary steps to address public health emergencies and reduce health risks, raise awareness of, prevent, control, and eradicate infectious diseases. It describes measures that should be taken to separate infected areas from non-infected areas to prevent the outbreak of the disease and give necessary instructions to prevent its recurrence in the affected area. It prescribes measures necessary to prevent unnecessary use and misuse of antibiotics in the treatment of infectious diseases; inspect homes, other accommodation, clinics, hospitals, and diagnostic centers or establishments where services are rendered to a person with an infectious disease; carry out physical and laboratory examinations of the person, and, if necessary, prescribe antibiotics, immunizations, or medicines; and instruct any person who has information on infectious diseases to send information to the Directorate. The Directorate is also instructed in the control of harmful pests, as well as the prevention and control of malaria or vector-borne diseases; the application of pesticides in homes and other accommodation; the use of mosquito nets, curtains, 
bedsheets, and other wearable fabrics; determining safe doses of pesticides; and access to any premises for the collection of information and breeding site management. If pesticides have been applied to buildings to control the carriers of infectious diseases, the Act prescribes that they should not be washed, limed, or plastered within the next 5 months, and that no action is to be taken on the building's surface.

The Act also lists duties and functions such as inspecting and testing food, beverages, or their ingredients for the purposes of identifying contamination or adulteration during preparation, storage, transportation, and distribution. Furthermore, the Act stipulates the isolation of a suspect who has contracted a contagious disease in a specific hospital, temporary hospital, establishment, or home, and the prevention of bacterial contamination and the removal or destruction of sources of infection, the prohibition of engineering, agricultural, or industrial projects which may cause the growth or spread of malaria and other infectious diseases, and the prohibition of the sale of pesticides containing long-lasting insecticide nets (LLIN) and insecticide nets which may interfere with the function of the seal or screen. The Act requires the temporarily closure of any markets, public places, stations, airports, seaports, and land ports to prevent the spread of infectious diseases, as well as prohibition of the entry, departure, or movement of aircraft, ships, vessels, buses, trains, and other vehicles from one place to another within the country to prevent the spread of infectious diseases and other functions performed by the government from time to time, including the discharge of assigned duties.

\section{Formation of the Advisory Committee}

The Advisory Committee consists of the Minister in Charge or the Minister of State or Deputy Minister in the Ministry of Health and Family Welfare, who acts as Chairman. Other members include the Secretary of the Department of Health Services, the Secretary of the Department of Medical Education and Family Welfare, at least one representative of the rank of Joint Secretary of the Ministry of Agriculture, at least one representative of the rank of Joint Secretary of the Ministry of Fisheries and Livestock, at least one representative of the rank of Joint Secretary of the Ministry of Environment and Forests, at least one representative of the rank of Joint Secretary in the Legislative and Parliamentary Affairs Department, the Director of the Disease Control Branch of the Directorate of Health, the Director of the Institute of Epidemiology, Disease Control and Research of the Directorate of Health, the Director General of the Directorate of Health, two persons nominated by the government and experienced in the relevant field, and at least one representative of the rank of Joint Secretary of the Directorate of Health Services who acts as a Member Secretary. If necessary, however, the government may co-opt any person who is an expert on infectious diseases to this Committee. The Act authorizes the Directorate of Health Services to provide necessary secretarial assistance to the Advisory Committee (Section 6).

\section{Function and Responsibility of the Advisory Committee}

The functions and responsibilities of the Advisory Committee are detailed in Section 7. The Committee is directed to provide necessary advice to the Health Directorate in formulating strategies to protect the people from the national and international spread of 
infectious diseases. It is entitled to review the use of antibiotics and other drugs used in the treatment of infectious diseases and to prohibit or direct the continuation of engineering, agricultural, or industrial projects that may cause the spread of infectious diseases. The Committee is authorized to provide necessary instructions to the Director General (DG) for effective implementation of the Act or any other Act prescribed by the rules (Section 7).

\section{Instructions of the World Health Organization}

The Act aims to prevent, control, and eradicate infectious diseases in order to protect the people from the national and international spread of infectious diseases. Under the Act, global alerts can be issued, and mutual assistance rendered in the case of an infectious disease outbreak so as to increase the capacity for risk management. Publications of the International Health Regulations and WHO cover the dissemination of education, the review of infectious disease spread, and protection of rights can be consistently used with necessary adaptations (Section 9).

\section{Sample Collection and Testing}

If there is a reason to believe that a person is infected with an infectious disease, officials are principally instructed to collect and test samples from that person, and carry out a pathological examination. If the presence of an infectious disease in the sample is confirmed in the pathological examination, the Authorized Official (AO) is obliged to inform the Civil Surgeon (CS) under his jurisdiction, with advice on what to do and to take any further necessary steps as per the instructions of the CS (Section 12). However, the Act does not cover how a patient should be treated when they are found to be infected by an infectious disease. More specifically, as institutional ethical committees in clinical settings are not commonplace in Bangladesh, the question is how scarce resources should be distributed in times of need, especially during the COVID-19 pandemic.

\section{Disinfection or Closure of Infected Places or Installations}

If any premises are found to be infected, access by the public to, and use of such premises are prohibited or restricted until they have been disinfected (Section 16). If disinfection is not possible, the Act instructs the owner of the facility to destroy it (Section 17).

\section{Provisions Relating to the Infected Areas, Goods, Patients, and Vehicles}

If it appears to the DG or any AO that the contagious disease in any particular area cannot be immediately contained or removed by taking appropriate healthcare measures, they may declare the area as infected and prohibit, restrict, and control entry (Section 11). The goods used by a person infected with a contagious disease shall be destroyed (Section 13). And if there is a reason to believe that the contagious disease may be transmitted from an infected person, the DG or any AO may direct the person to be isolated or transferred to a different location (Section 14). If a vehicle or form of 
transportation is contaminated with an infectious disease, officers are instructed to disinfect it (Section 18). This means that the arrival of flights, sea vessels, buses, trains, or other vehicles can be prohibited under this Act so as to contain the spread of contagious diseases. Under Section 20, the Act stipulates that an infected patient who has died of an infectious disease shall be buried or disposed of in accordance with the relevant regulations.

\section{Prohibition on Import and Export}

The Act completely prohibits the import and export of infected products containing human tissues or parts, or any harmful organism or substance or part or component in accordance with the rules made under this Act (Section 22).

\section{Punishments for Law Breakers}

Sections 24, 25, and 26 of the Act stipulate penal provisions. If a person transmits or contributes to the spread of an infectious disease, or conceals the risk of infection from another person when he/she comes into contact with them, or enters an establishment despite knowing their infection status, such an act is considered as an offense punishable by imprisonment for a term not exceeding 6 months and/or a fine not exceeding BDT 100,000 (approximately 1180 USD) (Section 24). If any person obstructs or impedes and refuses to carry out any instructions, the DG, the CS, or the AO shall impose imprisonment for a term not exceeding 3 months and/or a fine not exceeding BDT 50,000 (approximately 590 USD) (Section 25). Section 26 of the Act penalizes the providing of false information. Any person who intentionally provides false or incorrect information regarding any contagious disease can be sentenced to a maximum of 2 months of imprisonment and/or a fine of BDT 25,000 (approximately 295 USD) (Section 26).

\section{Ethical Issues in Resource Allocation in Times of Pandemic}

Healthcare services in Bangladesh are delivered by public and private institutions, nongovernmental organizations (NGOs), and international donor agencies (IDAs) (WPRO 2015). The healthcare system in Bangladesh is steered by the MOHFW, which offers policy suggestions for the two divisions of health services, and medical education and family welfare. Upon receiving policy directions from the MOHFW, Health Services Division and Medical Education and Family Welfare Division implement such policies through hospitals and clinics throughout the country (Government of Bangladesh 2018). Public healthcare services are generally provided by the primary, secondary, tertiary, and community-level hospitals and community clinics (Government of Bangladesh 2018). These hospitals and clinics provide promotive, preventive, and curative care for outpatients and inpatients. At the top, tertiary healthcare services are provided by hospitals and institutes located in divisional cities and the capital city in Bangladesh. Secondary healthcare services are offered by district hospitals. Publicly funded medical college hospitals and institutes also provide tertiary and secondary healthcare services. Primary healthcare services are delivered by sub-district hospitals 
in rural areas. Community healthcare services are provided by the Union and Ward domiciliary healthcare providers in remote areas. Privately funded hospitals and clinics mainly run on a for-profit basis with tertiary-level high-standard international hospitals (Government of Bangladesh 2018). As NGO- and IDA-funded hospitals and clinics are very few in the country, affluent patients often go private hospitals and clinics for their treatment while a vast majority of the poor and middle-class Bangladeshis depend on public-funded healthcare facilities. Thus, the government of Bangladesh is constitutionally committed to providing basic healthcare services and medical necessities to its people (article 15, The Constitution of the People's Republic of Bangladesh 1972). Article 19(2) of the Bangladeshi constitution therefore states that "the state shall adopt effective measures to remove social and economic inequality between men and women and to ensure the equitable distribution of wealth among citizens, and of opportunities in order to attain a uniform level of economic development throughout the Republic" (The Constitution of the People's Republic of Bangladesh 1972). The government thus uses most of the healthcare budget for priority areas in healthcare including the provision of clean drinking water, sanitation, population control, prevention of communicable and infectious diseases, and family planning (Rashid 2004).

Financial allocation in healthcare in Bangladesh is very limited compared with that of other countries in the South Asian Association for Regional Cooperation (SAARC) region with a relatively similar socio-economic status. For instance, Bangladesh spends less than $2.5 \%$ of its gross domestic product (GDP) on healthcare while the Maldives spends roughly $9 \%$ and Nepal spends more than 5.5\% (World Bank 2017). Allocation of other resources in healthcare such as healthcare staff is also limited in terms of demand. The condition is very acute in public hospitals. For example, Bangladesh has one physician for every 1847 people while the ratio in government hospitals is 1 to 6579 (The Financial Express 2018). Government hospitals always remain overcrowded, as most of the treatments, drugs, and medicines are provided free of charge or at subsidized prices. Conversely, privately funded hospitals are costly, aiming to provide treatment for the well-off sections of society, and are truly unaffordable for the vast majority. As a result, physicians in public hospitals are always busy providing care to these people. Lack of skilled manpower, infrastructural limitations, inadequacy of machinery and laboratories, lack of long-term planning, irregularities, and lack of oversight mechanisms make the healthcare system worse (Government of Bangladesh 2018). These pre-existing systemic problems and deficiencies in the public healthcare delivery system of Bangladesh make the situation more vulnerable during a pandemic. Despite the Act providing a legal framework for pandemic preparedness and for measures to raise awareness, as well as prevent, control, and eradicate infectious diseases, the absence of an ethical decision-making framework often creates dilemmas for healthcare professionals and front-line health workers. These staffs are faced with difficult decisions around how, where, and to whom medical resources should be distributed. Who will be prioritized for such resources? When should healthcare workers either deny or cancel treatments (Thompson et al. 2006)? Healthcare professionals and front-line health staff thus become vulnerable. Obviously, healthcare workers are professionally bound to offer care to the ill during a pandemic (Thompson et al. 2006), but Bangladeshi policy makers must consider these dilemmas of healthcare professionals and front-line health workers who routinely find it difficult to make these tragic decisions about the provision of scarce resources during a 
pandemic. This vulnerability can be overcome in countries where institutional ethics committees function effectively. In developed countries, ethics committees in the clinical setting have been working closely with physicians, healthcare staff, and hospital authorities in the development of clinical healthcare guidelines and policies determining who should receive care and on what basis, how a patient should be treated, and when treatment should be withheld or withdrawn (Litewka and Heitman 2020). These guidelines help healthcare professionals to establish how scarce resources should be used in critical times of need (Litewka and Heitman 2020), but are unfortunately absent in almost all publicly funded hospitals in Bangladesh.

Besides research, ethical committees are well-established in institutional structure and provide clinical ethical advice and consultation on the treatment of patients in developed countries (Litewka and Heitman 2020). They are uncommon in Bangladesh as medical ethics infrastructures only exist within research settings (Nurunnabi 2014). The reason is that formal ethical education has been a common feature of medical curricula in Western developed countries (Miyasaka et al. 1999) whereas very few healthcare professionals have this training in Bangladesh. As a result, overburdened healthcare professionals are often forced to decide between providing care on the basis of materialistic factors, and being guided by policy. There is no consensus among healthcare professionals as to how scarce resources should be allocated and distributed to patients. This is crucial in a time of emergency, especially in the time of the COVID19 pandemic. Under the Act, if the presence of an infectious disease in someone is confirmed by pathological examination, the AO must inform the CS in order to receive advice on what further necessary steps must be taken to treat infectious patients (Section 12). As mentioned earlier, a COVID-19 patient was first identified in Bangladesh on 8 March and the number of affected patients has been gradually on the rise. As of 9 July 2020, a total of 175,494 people had been infected with the COVID-19 virus and deaths amounted to 2238 (Worldometer 2020). The ethical question that inevitably arises is how the healthcare system should allocate treatment when so many COVID-19 patients require care in Bangladesh.

Medical resources such as medications, medical beds, intensive care units (ICUs), and ventilators are already scarce, globally, amid the COVID-19 pandemic. Clinical care providers often find it difficult to make decisions as to who should receive the already scarce healthcare resources. These resources include hospital beds, ventilators, beds in ICUs, and COVID-19 tests. On the other hand, privately funded hospitals were almost locked down for the purpose of treating COVID-19 patients. Only a few private hospitals have recently been offering care for COVID-19 patients. Along with affluent patients, the vast majority of poor and middle-class COVID-19 patients still have to depend on underfunded public hospitals. It has created huge burdens on publicly funded hospitals. Healthcare professionals in Bangladesh thus need to make challenging decisions about who should receive scarce medical resources between the haves and have-nots. As huge demand outstrips scarce supply, a vast majority of COVID-19 patients are denied testing and treatment while elites who are able to influence healthcare systems reserve beds (Corraya 2020). Many poor and middle-class COVID-19 patients are turned away from hospitals without receiving care (Akhter 2020; UNDP Bangladesh 2020; Kashem 2020), while many elites can use governmentsponsored specialized hospitals to receive COVID-19 treatment (Siddiqui 2020). A number of government and non-government official elites have made contracts with a 
number of private hospitals recently to facilitate COVID-19 treatment as reported by newspapers and the media. Giving priority to one group of people by depriving another is unfair in a time of need, especially amid the COVID-19 pandemic. The unequal distribution of wealth and power in society and structural deficits in public healthcare delivery systems are contributory factors to unfair allocation of scare medical resources. The allocation of resources for treating elites violates the biomedical principles of nonmaleficence, as healthcare resources should not be reserved for the benefit of certain people if it could be harmful to others in society (Beauchamp and Childress 2009). These criteria also violate the biomedical principle of procedural justice that requires fairness of the processes by which clinical decisions are made and implemented in allocating scarce healthcare resources and medical treatments (Beauchamp and Childress 2009; Maiese and Burgess 2020). Resources must be impartially allocated and consistently implemented in order to generate "unbiased decisions" and ensure "fair treatment" (Maiese and Burgess 2020). One of the goals of a public health service is to maintain a high level of health throughout society, not to secure the best possible health of a few (Gostin 2010). These aspects are compromised in the distribution of scarce resources in Bangladesh during the COVID-19 pandemic. The unfair process of distributing scarce resources thus negatively affects the health of a larger sector of the population. The unfair allocation criteria also violate the principle of a right to health that is underwritten by the Constitution of the People's Republic of Bangladesh (1972). These actions erode Bangladeshi trust in the healthcare system and undermine societal cohesion. Public policies and practices in healthcare must be aimed at creating a system that can ensure benefits to all by allocating scarce medical resources in the fairest and most transparent way possible.

What is the most basic tension in the society that the Act was designed to solve? The Act was designed to solve the problem of how the government can legitimately restrict individual liberty in order to protect the health of a larger section of the public during the COVID-19 pandemic. Usually public health laws are designed to provide a framework for ethical decision-making that inspires government power to move towards establishing justice through fair procedures. Public health laws like the Act empower the government to use legal powers to restrict individual liberty and enable public health to be protected from serious harm (Thompson et al. 2006). Obviously, individuals who have the means to do so can purchase anything they wish (e.g., food, motorbike, and housing) but they cannot secure their own health alone. As such, they need to collaborate on building a shared healthcare infrastructure and resources through community activities (Gostin 2010) to protect public health from harm through fair practice. However, the Act lacks any ethical decision-making framework for allocating scarce medical resources such as mechanical ventilator beds and COVID-19 medications. This in turn creates a burden on healthcare professionals and front-line health workers around which groups and individuals are offered care, and on what basis. Obviously, access to healthcare is limited if a number of patients require care, even in countries that have universal healthcare coverage (UHC) (Dawson and Verweij 2020). However, healthcare systems in countries with UHC ensure equitable access for patients through fair practice. Bangladeshi policy makers should consider building a framework and developing shared resources through fair practice that can resolve unintended and unavoidable ethical difficulties of resource allocation. Healthcare services must be tasked with ensuring that any government action does not 
unintentionally increase existing unfairness and inequality (Dawson and Verweij 2020). Thus, the review and substantial overhaul of the stipulations in the Act is necessary, requiring the establishment of an effective framework for ethical decisionmaking in each hospital in Bangladesh, and parliamentary guidelines on how to allocate scarce resources in the fairest way possible for the benefit of society as contribution to pandemic preparedness and response (Thompson et al. 2006). These changes are necessary because the law is not solely a structural framework for directing the practice of healthcare professionals but it also provides the basis for societal conduct to which adherence from healthcare professionals is necessary (Willcox 1964). Willcox (1964) explains the viewpoint that the law is the servant in enforcing the conduct of healthcare professionals in the protection of public health; it is also the master in setting the bounds beyond which regulations are not able to impact the rights of an individual. The physicians are furthermore also the servants in that they must adhere to the codes of conduct of non-maleficence and equality of treatment, but are the masters in a system where without an ethical framework stipulating the ethical provision of treatment to all irrespective of wealth and privilege, they can assign scarce resources on a whim however they see fit, or to the highest bidder. Setting up ethical framework in the Act is imperative in ensuring that healthcare professionals play a dual role in the healthcare system of Bangladesh. Otherwise, the stipulation of the Act is consistent with WHO recommendations.

This study does not intend to underscore the severity of disease burden and the mortality during the COVID-19 pandemic; rather, it intends to address how Bangladeshi policy makers can resolve pre-existing systemic healthcare challenges and structural deficiencies with regard to the distribution of scarce medical resources through fair practice. Rittel and Webber (1973) argue that allocating a medical resource is a "wicked problem," which is inherently impossible to solve because pre-existing structural problems in changing times and priorities are often difficult for policy makers to recognize. As such, these problems often go unsolved (Rittel and Webber 1973). A major crisis in public health delivery results from the healthcare system needs overwhelming the available medical resources (Thompson et al. 2006). As these resources are scarce, the answer to the ethical question needs to be addressed in determining how such scarce resources are to be distributed in order to ensure favorable outcomes for the greatest number of Bangladeshis. The answer is that resources should be allocated to those who are in the greatest medical need, or those who are at most risk. Thus, the favorable outcome is saving as many lives as possible. However, decisions in resource allocation often involve difficult judgments on how much priority is to be given to those who are worst off (Daniels 2016). The WHO directs that priority can be given in allocating resources in terms of their scarcity: if little scarcity exists, resource allocation should be on the principle of a first come, first served basis; when resources become increasingly scarce, distributions prioritize those most in need; and with greater scarcity, the allocation of resources should aim to maximize human benefit (WHO 2020). Thus, the priority-setting principles are to be defined in the healthcare delivery system of Bangladesh, with the aim of maximizing the benefit as a way of producing the greatest number of favorable outcomes (Thompson et al. 2006). These priority-setting principles can place a disproportionate burden on vulnerable populations such as the aged, physically challenged, and socially disadvantages. The ethical framework might be the same in different crises, but can lead to different ethical decisions based on the 
particular context of the disproportionate burden and of the factors that define the vulnerable populations (WHO 2020). For example, pregnant women are generally more vulnerable to dengue fever, and carry a higher risk of mortality. In contrast, older adults are more vulnerable and have higher risk of deaths in the current COVID-19 pandemic, and as such they should be prioritized in the allocation of resources. If allocation decisions are to be made on this basis, people will be more likely to accept healthcare outcomes whatever care they receive. If people believe that the decisionmaking process in resource allocation is fair (Maiese and Burgess 2020), they will not complain to the authorities in the event of an unfavorable outcome. A fair decisionmaking process for the allocation of medical resources is necessary to ensure the ethical standards that can engender Bangladeshis' solidarity and trust in the healthcare system.

\section{Compliance with Ethical Standards}

Conflict of Interest The authors declare that they have no conflict of interest.

\section{References}

Akhter, Farida. 2020. COVID-19 and healthcare denial. New Age, 2 April 2020. https://www.newagebd.net/ article/103590/covid-19-and-healthcare-denial. Accessed 26 June 2020.

Beauchamp, Tom L., and James F. Childress. 2009. Principles of Biomedical Ethics, sixth edition. New York: Oxford University Press.

Corraya, Sumon. 2020. COVID-19 patients turned away by Dhaka hospitals. AsianNews (Pontificio Istituto Missioni Estere), 11 June 2020. http://www.asianews.it/news-en/COVID-19-patients-turned-away-byDhaka-hospitals-50323.html . Accessed 26 August 2020.

Daniels, Norman. 2016. Resource allocation and priority setting. In Public health ethics: cases spanning the globe, ed. Drue H. Barrett, Leonard W. Ortmann, Angus Dawson, Carla Saenz, Andreas Reis, and Gail Bolan, 61-94. Cham: Springer. https://doi.org/10.1007/978-3-319-23847-0_3.

Dawson, Angus, and Marcel Verweij. 2020. Law, ethics, and politics in the face of a global pandemic. Public Health Ethics 13 (1): 1-3. https://doi.org/10.1093/phe/phaa023.

Gostin, Lawrence O. 2010. Mapping the issues: public health, law and ethics. In Public health law and ethics: a reader, second edition. New York and Berkeley: Milbank Memorial Fundand the University of California Press. https://scholarship.law.georgetown.edu/facpub/374/. Accessed 2 October 2020.

Government of Bangladesh. 2018. Health bulletin 2017. Government of Bangladesh. https://dghs.gov.bd/ index.php/en/home/4364-health-bulletin-2017. Accessed 26 August 2020.

Infectious Diseases (Prevention, Control and Eradication) Act. 2018. http://bdlaws.minlaw.gov.bd/act-details1274.html?lang=en. Accessed 2 July 2020.

Kashem, Abul. 2020. Private hospitals to lose licence for refusing emergency patients or anybody. The Business Standard, 11 May 2020. https:/tbsnews.net/bangladesh/health/private-hospitals-lose-licencerefusing-covid-19-patients-80218. Accessed 2 July 2020.

Litewka, Sergio G., and Elisabeth Heitman. 2020. Latin American healthcare systems in times of pandemic. Developing World Bioethics 20 (2): 69-73. https://doi.org/10.1111/dewb.12262.

Maiese, Michelle and Heidi Burgess. 2020. Types of justice. Beyond Intractability, July 2020. http://www. beyondintractability.org/essay/types-of-justice. Accessed 27 August 2020.

Mamun, Mohammed A., Jannatul Mawa Misti, Mark D. Griffiths, and David Gozal. 2019. The dengue epidemic in Bangladesh: risk factors and actionable items. Lancet 394 (10215): 2149-2150. https://doi. org/10.1016/S0140-6736(19)32524-3.

Miyasaka, Michio, Akira Akabayashi, Ichiro Kai, and Gen Ohi. 1999. An international survey of medical ethics curricula in Asia. Journal of Medical Ethics 25 (6): 514-521. https://doi.org/10.1136/jme.25.6.514.

Nurunnabi, Abu Sadat Mohammad. 2014. Institutional review board (IRB): its role and responsibility in making research ethical. Bangladesh Journal of Bioethics 5 (1): 5-10. https://doi.org/10.3329/bioethics. v5i1.18442. 
Rashid, Harun Ur. 2004. Health delivery system for renal disease care in Bangladesh. Saudi Journal of Kidney Diseases and Transplantation 15 (2): 185-189.

Rittel, Horst W.J., and Melvin M. Webber. 1973. Dilemmas in a general theory of planning. Policy Sciences 4: 155-169. https://doi.org/10.1007/BF01405730.

Siddiqui, Kamran. 2020. Number of VIPs growing among Covid-19 cases. The Business Standard, 15 June 2020. https://tbsnews.net/coronavirus-chronicle/covid-19-bangladesh/number-vips-growing-amongcovid-19-cases-93322. Accessed 28 June 2020.

The Constitution of the People's Republic of Bangladesh. 1972. http://bdlaws.minlaw.gov.bd/act-367.html. Accessed 9 July 2020.

The Daily Star. 2020. Govt issues gazette enlisting coronavirus as 'communicable disease'. The Daily Star, 23 March 2020. https://www.thedailystar.net/online/news/govt-issues-gazette-enlisting-coronaviruscommunicable-disease-1884808. Accessed 17 May 2020.

The Financial Express. 2018. Bangladesh has one doctor for every 1847 people. The Financial Express, 19 February 2020. https://thefinancialexpress.com.bd/health/bangladesh-has-one-doctor-for-every-1847people-1519053209. Accessed 3 May 2020.

Thompson, Alison K., Karen Faith, Jennifer L. Gibson, and Ross E.G. Upshur. 2006. Pandemic influenza preparedness: an ethical framework to guide decision-making. BMC Medical Ethics 7: E12. https://doi. org/10.1186/1472-6939-7-12.

UNB. 2019. Govt confirms 164 dengue deaths in 2019. UNB, 9 January 2020. https://www.unb.com.bd/ category/Bangladesh/govt-confirms-164-dengue-deathsin-2019/40746. Accessed 26 August 2020.

UNDP Bangladesh. 2020. Covid-19: a reality check for Bangladesh's healthcare system. UNDP Bangladesh, 3 May 2020. https://www.bd.undp.org/content/bangladesh/en/home/stories/a-reality-check-forbangladesh-s-healthcare-system.html. Accessed 26 June 2020.

WHO. 2020. Ethics and COVID-19: resource allocation and priority-setting. World Health Organization. https://www.who.int/ethics/publications/ethics-andcovid-19-resource-allocation-and-priority-setting/en/. Accesed 2 September 2020.

Willcox, Alanson W. 1964. The role of law in improving public health. Public Health Reports 79 (8): 647653.

World Bank. 2017. Current health expenditure (\% of GDP). World Health Organization Global Health Expenditure database. https://data.worldbank.org/indicator/SH.XPD.CHEX.GD.ZS. Accessed 21 August 2020.

World Bank. 2018. Population density (people per sq. km of land area) - Bangladesh. Food and Agriculture Organization and World Bank population estimates. https://data.worldbank.org/indicator/EN.POP. DNST?locations=BD. Accessed 2 September 2020.

Worldometer. 2020. COVID-19 coronavirus pandemic. Worldometer. https://www.worldometers.info/ coronavirus/\#countries. Accessed 9 July 2020.

WPRO. 2015. Bangladesh health system review. Health systems in transition, volume 5, number 3. Manila: World Health Organization Regional Office for the Western Pacific. https://apps.who.int/iris/handle/ 10665/208214. Accessed 26 August 2020.

Publisher's Note Springer Nature remains neutral with regard to jurisdictional claims in published maps and institutional affiliations. 